\title{
ACID MINE WATER TREATMENT WITH FILTRATION SYSTEM USING CERAMIC MEMBRANE
}

[Rachmawati Apriani]

\begin{abstract}
Acid mine drainage is an environmental pollutant waste arising from mining activities. Acid mine drainage ( $A A T)$ sulphida formed when certain minerals that exist in rocks exposed to conditions where there is water and oxygen (as the main factor) which causes the oxidation processes and produces water with acidic conditions. The purpose of this study is to apply the use of ceramic membranes in acid mine water treatment unit and improve the quality of the acid mine water to be safely discharged into the environment. In this study, acid mine water through the process of coagulation, filtration using a filter size of $5 \mathrm{~lm}$, activated carbon and ceramic membrane. Varied parameters are operating pressure differential is $10.3 ; 15.3 ; 18.3$ psi with operation time is $15,30,45$ and 60 minutes. The results showed that the ceramic membrane made from clay, rice bran and iron powder with a composition of $87.5 \%$ clay, $10 \%$ rice bran and $2.5 \%$ iron powder and clay composition of $77.5 \%, 20 \%$ rice bran and $2.5 \%$ iron powder resulted in a decrease permeate flux and decrease the metal content such as $\mathrm{Fe}, \mathrm{Mn}$ and $\mathrm{Al}$.
\end{abstract}

Keywords : ceramic membranes, acid mine drainage, filtration

\section{Introduction}

Waste is the residue resulting from an activity and production process, both at household, industrial, mining, and so on. Industrial wastewater treatment problem adequately is much more complex and more difficult than household waste. Most industrial waste produce waste that is liquid or solid that is still rich with organic substances that are susceptible to decomposition. Most of the existing industry throw waste into open waters, resulting in a relatively short time there will be a foul odor as a result of waste fermentation. The entire industry entrepreneurs who will dispose of waste are required to process beforehand to prevent environmental pollution in the vicinity.

Acid mine drainage is an environmental pollutant waste resulting from mining activities. Waste is due to the oxidation of the mineral pyrite $\left(\mathrm{FeS}_{2}\right)$ and other sulfide minerals exposed surface of the ground in the process of making mineral mines. Chemical and biological processes of materials that produce sulfate mineral with a low acidity level. Directly or indirectly, a low level of acidity which affect the quality of the environment and living organisms.

Acid mine drainage (AAT) formed when certain existing mineral sulphides in the rock are exposed to conditions where there is water and oxygen (as main factor) which cause oxidation and produce water with acidic conditions. AAT is a term used to refer to the acidic water arising from mining activities, to distinguish the acid water incurred by

Rachmawati Apriani other activities such as excavation for the construction of building foundations, creation of ponds, and so on. The location of the mining area in the formation of acid mine water will have a negative impact on the environment.The impact that can be caused by acid mine water is environmental pollution, wherein the composition or water content of the affected area will be changed so as to reduce soil fertility, damage the health of the surrounding community, and can lead to corrosion of the mining equipment.

The method is expected to be used to minimize problems in the wastewater treatment industry, especially liquid waste PT. Bukit Asam is by using a ceramic membrane technology. This ceramic membrane technology has advantages over organic membranes or polymers such as long service life, easy and efficient in cleaning, chemical and thermal resistance are better, and have a high mechanical strength. Another advantage of membrane technology is the separation with membranes did not require additional chemical substances and also the very minimum energy needs. The membranes can act as a very specific filter.

Bran is waste grain processing, and not for human consumption, so as not to compete in its use. Rice bran is the result of the rest of pulverization or milling grain rice. Bran is composed of three different sections which each contain substance.

\section{Research Methodology}

\section{A. Time and Place Research}

The research was started in April to May 2013 in Separation Technology Laboratory and Laboratory Equilibrium Chemical Engineering Department of the Faculty of Engineering, University of Sriwijaya

\section{B. Preparation of Raw materials}

Before the waste treatment process is done, the waste PT. Bukit Asam must first coagulated using a coagulant PAC (Poly Aluminium Chloride) with coagulator apparatus equipped with a stirrer. It is intended that the suspended particles will quickly settle to get a clearer liquid wastes and heavy metals accelerate the separation process using membranes.

\section{Schematic Design Membrane}

Designed ceramic membrane tube-shaped, made of a mixture of clay and iron filings as well aditive and rice husk with the following dimensions: inner diameter $=5 \mathrm{~cm}$, outside diameter $=7 \mathrm{~cm}$, thickness $=1 \mathrm{~cm}$, length $=25 \mathrm{~cm}$. Housing made of glass fiber membrane with the following 
dimensions: outer diameter $=9 \mathrm{~cm}$, internal diameter $=8.5$ $\mathrm{cm}$, length $=60 \mathrm{~cm}$.

\section{Research Procedure}

Acid mine drainage from PT. Bukit Asam already coagulated using coagulant PAC (Poly Aluminium Chloride) is inserted into the tank (tedmond) waste storage size of $500 \mathrm{~L}$. Then, with the help of pressure pumps, waste water PT. Bukit Asam from the storage tank flowed into housing-1 that contains sand filter. Pressure pump set 25.30 and 33 psi. Then the waste water that has been filtered by sand filter channeled to housing-2 which contains a filter with a pore diameter of $5 \mathrm{~mm}$. Then the waste water that has passed through the filter, flowed again into housing-3 which contains activated carbon as adsorbent. Then the waste water that has passed through the activated carbon is passed again to the housing-4 which contains the membrane. The membranes are used to vary the pore diameter and composition. Waste water that has passed through the membrane is collected in a container. Sampling of waste water that has passed through the complete separation process that is taken every 15 minutes; 30 minutes; 45 minutes ; 60 minutes.

\section{Result and Discussion}

\section{A. Research Result}

TABLE 1. RESULTS OF ANALYSIS OF $\mathrm{pH}, \mathrm{Fe}, \mathrm{Mn}$ and $\mathrm{Al}$ FROM WASTE ACID MINE DRAINAGE

\begin{tabular}{cccc}
\hline Parameter Test & Unit & $\begin{array}{c}\text { Inlet east } \\
\text { pit }\end{array}$ & $\begin{array}{c}\text { Outlet } \\
\text { east pit }\end{array}$ \\
\hline $\mathrm{pH}$ & & 3,30 & 4,17 \\
$\mathrm{Fe}$ & $\mathrm{mg} / \mathrm{liter}$ & 2,08 & 0,04 \\
$\mathrm{Mn}$ & $\mathrm{mg} / \mathrm{liter}$ & 7,9 & 7,30 \\
$\mathrm{Al}$ & $\mathrm{mg} / \mathrm{liter}$ & 10,11 & 8,20 \\
\hline
\end{tabular}

\section{B. Discussion}

a. Manufacture of Ceramic Membrane Manufacture of ceramic membrane made of clay, rice

bran and iron filings in a certain ratio. Ceramic membrane made through several processes, namely the selection of raw materials, kneading, forming (molding), drying and burning (sintering). Each stage of the processing greatly affects porosity ceramic membrane. Membrane are used consisting of:

1. Membrane $1:$ the membranes with a composition of $77.5 \%$ clay : $20 \%$ rice bran: $2.5 \%$ iron powder

2. Membrane 2: the membrane with a composition of $87.5 \%$ of clay: $10 \%$ rice bran: $2,5 \%$ iron powder.

Comparison of the composition is determined based on studies that have been done before, namely $77.5 \%$ clay: $20 \%$ rice bran: $2,5 \%$ iron powder. Based on the research results, the membrane with a composition of $87.5 \%$ of clay: $10 \%$ rice bran: $2,5 \%$ iron powder has a mechanical resistance that is stronger than the membrane with a composition of $77.5 \%$ of clay: $20 \%$ rice bran: $2,5 \%$ iron powder.
PTBA waste water treatment is done by varying the feed flow rate to the pressure difference $(\Delta \mathrm{P}) 10.3 ; 15.3$ and 18.3 psi. Observations were made for 15, 30, 45 and 60 minutes. In this study, the addition of rice bran aims to form pores membrane. Size of grain rice bran has an influence on the permeability of the membrane. Grain and size play an important role in the process of diffusion. Small granules that cause wider surface area. The surface area plays an important role in improving permesi membranes, namely by reducing the grain size, the permeability increases. Reduced grain size will expand so that the membrane surface membrane permeation increases. The addition of iron powder in the manufacture of ceramic membranes aims to strengthen the mechanical resistance of ceramic membrane.

b. Influence of operating time for the permeate flux membranes

In this study, the operating time used is $15,30,45$ and 60 minutes. All membrane flux decline. A decrease in membrane flux can occur because the gel layer formation and blockage of the pores in the membrane. Decrease in flux may increase due to the pressure difference and the operating time is used. Flux decline caused also due to volume decreases with the longer operating time. A decrease in the flux occurs when the pressure difference increases.

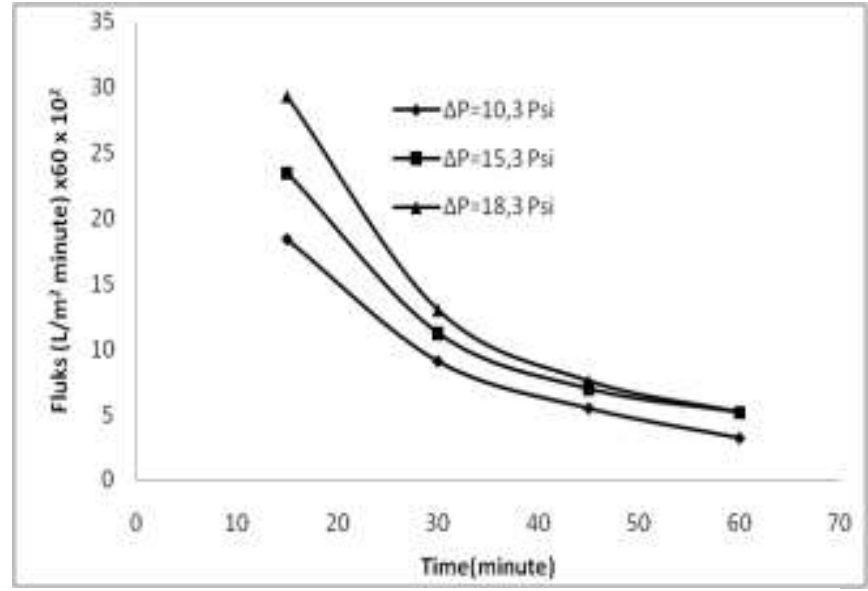

Figure 1. Effect of flux against time with a composition of $77.5 \%$ clay, $20 \%$ rice bran, $2.5 \%$ iron powder with rice bran size of $500 \mu \mathrm{m}$ and an iron powder of $250 \mu \mathrm{m}$.

From the picture above shows a decrease in flux with increasing operating time. A decrease in the flux occurs when the pressure difference increases. In the filtration system of the highest is designed fluks look at the condition of the pressure difference $\Delta \mathrm{P}=18.3$ psi with a time of 15 minutes $29.30 \times 102 \mathrm{~L} / \mathrm{m}^{2} \mathrm{~h}$ and the lowest flux seen in conditions of pressure difference $\Delta \mathrm{P}=10.3$ psi at 60 minutes by $3.18 \times 102 \mathrm{~L} / \mathrm{m}^{2} \mathrm{~h}$ with the composition of $77.5 \%$ clay, $20 \%$ rice bran $(500 \mu \mathrm{m})$ and iron powder $2.5 \%$ $(250 \mu \mathrm{m})$

c. Influence of operating time for the permeate flux membranes 2 
Proc. of The Third Intl. Conf. On Advances in Applied Science and Environmental Technology - ASET 2015

Copyright $\odot$ Institute of Research Engineers and Doctors, USA .All rights reserved.

ISBN: 978-1-63248-084-2 doi: 10.15224/ 978-1-63248-084-2-47

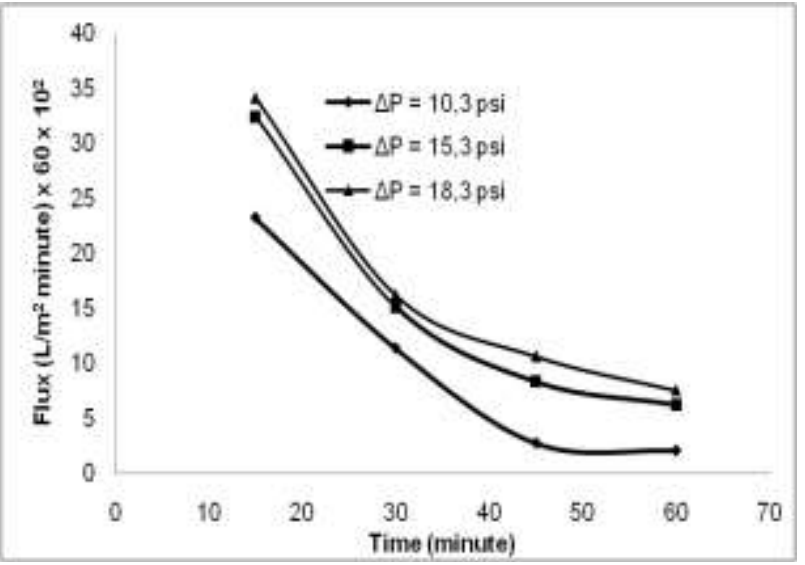

Figure 2. Effect of flux against time with clay composition of $87.5 \%$, rice bran $10 \%, 2.5 \%$ iron powder with rice bran size of $250 \mu \mathrm{m}$ and iron filings

From the picture above shows a decrease in flux with increasing operating time. A decrease in the flux occurs when the pressure difference increases. In the filtration system of the highest designed fluks look at the condition of the pressure difference $\Delta \mathrm{P}=18.3$ psi in 15 minutes at 34.14 $\mathrm{x} 102 \mathrm{~L} / \mathrm{m}^{2}$ hour and the lowest flux seen in conditions of pressure difference $\Delta \mathrm{P}=10.3 \mathrm{psi}$ with a time of 60 minutes of $2.04 \times 102 \mathrm{~L} / \mathrm{m} 2$ hour with a composition of $87.5 \%$ clay, $10 \%$ rice bran $(250 \mu \mathrm{m})$ and iron powder $2.5 \%(250 \mathrm{~m})$. From the figure above shows a decrease in flux with increasing operating time. A decrease in the flux occurs when the pressure difference increases. In the filtration system designed seen that the pressure differences $\Delta \mathrm{P}=15.3$ psi indicates a decrease in the flux was relatively good for filter with clay composition of $87.5 \%, 10 \%$ rice bran $(500 \mu \mathrm{m})$ and iron powder $2.5 \%(250 \mu \mathrm{m})$. Theoretically increase the operating pressure will increase the rate of the permeate. However, the increase in pressure can also increase the likelihood of fouling on the membrane surface. Fouling can be caused due to solute particles contained in the waste water.

d. Results Analysis of Fe content in the permeate in the membrane

TABLE 2. DECREASED LEVELS OF IRON (Fe) TO TIME AND THE OPERATING PRESSURE FOR THE MEMBRANE (PARTICLE SIZE OF RICE BRAN 500 $\mu \mathrm{m}$ - IRON POWDER 250 $\mu \mathrm{m})$

\begin{tabular}{cccc}
\hline $\begin{array}{c}\text { Time } \\
(\text { minute })\end{array}$ & $\begin{array}{l}\text { Fe Content } \\
(\Delta \mathrm{P}=10,3 \\
(\%)\end{array}$ & $\begin{array}{c}\text { Fe Content } \\
(\Delta \mathrm{P}=15,3 \mathrm{psi}) \\
(\%)\end{array}$ & $\begin{array}{c}\text { Fe Content } \\
(\Delta \mathrm{P}=18,3 \mathrm{psi}) \\
(\%)\end{array}$ \\
\hline 15 & 93,27 & 98,08 & 92,79 \\
30 & 93,75 & 92,79 & 89,42 \\
45 & 97,60 & 91,83 & 93,75 \\
60 & $\mathbf{0 7 7 0}$ & 0760 & $\mathbf{0 7} 70$
\end{tabular}

e. Analysis of the results of Mn concentration in the permeate in the membrane
TABLE 3. DECREASED LEVELS OF MANGANESE (Mn) TO TIME AND THE OPERATING PRESSURE FOR THE MEMBRANE (PARTICLE SIZE OF RICE BRAN 250 $\mu$ - IRON POWDER 500 $\mu \mathrm{m})$

\begin{tabular}{cccc}
$\begin{array}{c}\text { Time } \\
(\text { minute })\end{array}$ & $\begin{array}{c}\text { Mn Content } \\
(\Delta \mathrm{P}=\mathbf{1 0 , 3} \mathrm{psi}) \\
(\%)\end{array}$ & $\begin{array}{c}\text { Mn Content } \\
(\Delta \mathrm{P}=15,3 \\
\mathbf{p s i})(\%)\end{array}$ & $\begin{array}{c}\text { Mn Content } \\
(\Delta \mathrm{P}=\mathbf{1 8 , 3} \mathrm{psi}) \\
(\%)\end{array}$ \\
\hline 15 & 13,21 & 5,66 & \\
30 & $\mathbf{6 , 9 2}$ & $\mathbf{5 , 6 6}$ & $\mathbf{3 , 1 4}$ \\
45 & $\mathbf{0 , 6 3}$ & $\mathbf{1 , 8 7}$ & $\mathbf{8 , 1 8}$ \\
60 & 5,66 & 4,40 & $\mathbf{4 , 4 0}$ \\
\hline
\end{tabular}

f. Analysis of the concentration of $\mathrm{Al}$ in the permeate in the membrane

TABLE 4. DECREASED LEVELS OF ALUMINIUM (Al) TO TIME AND THE OPERATING PRESSURE FOR THE MEMBRANE (PARTICLE SIZE OF RICE BRAN 250 $\mu$ - IRON POWDER 500 $\mu \mathrm{m})$

\begin{tabular}{cccc}
$\begin{array}{c}\text { Time } \\
(\text { minute })\end{array}$ & $\begin{array}{c}\text { Al Content } \\
(\Delta \mathrm{P}=10,3 \\
\mathrm{psi})(\%)\end{array}$ & $\begin{array}{c}\text { Al Content } \\
(\Delta \mathrm{P}=15,3\end{array}$ & $\begin{array}{c}\text { Al Content } \\
(\Delta \mathrm{P}=18,3\end{array}$ \\
\hline 15 & $\mathbf{p s i})(\%)$ & $\mathrm{psi})(\%)$ \\
30 & $\mathbf{8 , 0 9}$ & $\mathbf{9 , 0 0}$ & 15,92 \\
45 & $\mathbf{0 , 1 0}$ & 12,96 & 13,95 \\
60 & 4,06 & $\mathbf{6 , 0 3}$ & 9,99 \\
& & 14,94 & 18,89 \\
\hline
\end{tabular}

\section{Conclusion}

Ceramic membranes are made from clay, rice bran and iron powder with a composition of $87.5 \%$ clay, $10 \%$ and $2.5 \%$ rice bran powder composition of $77.5 \%$ iron and clay, $20 \%$ rice bran and $2.5 \%$ iron powder resulted in a decrease in the permeate flux and decreased content of metals such as $\mathrm{Fe}, \mathrm{Mn}$ and $\mathrm{Al}$. The percentage decrease in the levels of $98.08 \% \mathrm{Fe}, \mathrm{Mn}$ content of $8.18 \%$ and $\mathrm{Al}$ of $18.89 \%$ was appropriate quality standard and safely discharged to the environment.

\section{References}

[1] Ashaghi, K. Shams et. al.2007.Ceramic Ultra and Nanofiltration Membranes for Oilfield Produced Water Treatment: A Mini Review.Departement of Biotechnology, University of Applied Sciences Giessen-Friedberg,Giessen,Germany.

[2] Aygun, A., dan T. Yilmaz.2010.Improvement of CoagulationFlocculation Processfor Treatment of Detergent Wastewaters Using Coagulant Aids,International Journal of Chemical and Environmental Engineering, Volume 1, No.2, 97-101

[3] Faulkner, B.B. 1996. Acid mine drainage treatment recommendations. Unpublished report for the West Virginia Mining and Reclamation Association, Charleston, WV.

[4] Gomes, Maria Carolina Sergi et. al.2010. Separation of biodiesel and Glycerol Using Ceramic Membranes.Departement of Chemical Engineering, State University of Maringa, Av.Colombo 5790, bloco D90, CEP 87020-900,Parana,PR,Brazil.

[5] Iqbal, M, Immanuel and S.Nasir.2010. Swamp Water Treatment as a Source Water Using Ceramic Membranes, The results of Student JurusanTeknik Chemistry, University of Sriwijaya.

[6] Kartikasari \& Monavita.2005.Pengolahan Acid Mine Wastewater premises Using Ceramic Membranes. Palembang: Sriwijaya University. 
Proc. of The Third Intl. Conf. On Advances in Applied Science and Environmental Technology - ASET 2015

Copyright $\odot$ Institute of Research Engineers and Doctors, USA .All rights reserved.

ISBN: 978-1-63248-084-2 doi: 10.15224/ 978-1-63248-084-2-47

[7] Nasir, S.2010.Kinerja Reverse Osmosis Membrane in Raw Water Treatment Containing Sodium and Calcium Ion

[8] Nasir, S, Anggraini, D and Agustina, A.2010.Aplikasi Ceramic Membrane in Liquid Waste Treatment, Outcome study Faculty of Engineering Department of Chemical Engineering Sriwijaya University, Palembang

[9] Nasir, S (2010), Making Filter Microfiltration of Clay and Fly Ash in Waste Water Treatment, Paper National Seminar on Chemical Engineering, University of Parahyangan

[10] Setiawan, Hendrix Yulis.2012. Membrane technology. Malang UB.Xuwen, HE et. al.2010.Treatment of Mine Water High ini Fe and Mn by Modified Manganese Sand.School of Chemical and environmental Engineering,China University of Mining \& Technology, Beijing 100083,China.

[11] Zhu, Yunqing et. al.2013.Hierarchical Porous Ceramic membrane with Energetic Ozonation Capability for Enhancing Water Treatment.Datian University of Technology, China.

About Author (s):

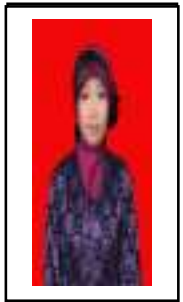

[Membrane Ceramic is the method to decrease the heavy metal content in acid mine water to improve the quality of the acid mine water to be safely discharged into the environment.] 